\title{
Gaining Perspective of an Industry's Readiness for Regulatory Change: A Case Study From the Aviation Industry
}

\author{
Damon Lercel ${ }^{1}$ \\ ${ }^{1}$ School of Aviation \& Transportation Technology, Purdue University, West Lafayette, United States \\ Correspondence: Damon Lercel, School of Aviation \& Transportation Technology, Purdue University, West \\ Lafayette, Indiana, United States. Tel: 1-765-494-7067.
}

Received: March 13, 2019

Accepted: April 4, 2019

Online Published: April 22, 2019

doi:10.5430/jms.v10n3p15

URL: https://doi.org/10.5430/jms.v10n3p15

\begin{abstract}
A change in regulatory policy regularly affects more than one organization and may involve an entire industry comprised of thousands of diverse organizations. These types of regulatory changes often encounter significant resistance from industry stakeholders as they often view new regulation with a certain level of skepticism, contributing to policy gridlock. A significant factor in whether any change initiative fails or succeeds is the organization's readiness for change. However, a preponderance of the organizational change research to date has focused on individuals, targeted small groups, or single organizations - little has focused on regulatory policy changes that may affect a very large and diverse industry group. By better understanding an industry's readiness for change, regulators may more effectively identify and understand the potential opposing forces, develop strategies to overcome these forces, and therefore may create a change vector. Recently, the Federal Aviation Administration proposed a major regulatory change affecting the United States' aviation repair station industry. This heavily debated regulation would require industry organizations to develop a formal Safety Management Systems. Thus far the regulation has met stiff industry resistance. This research attempted to gain perspective of the industry's readiness for change and found their overall readiness level was low. Although this research was limited in scope and intended as an initial exploration of change readiness concepts across a large industry faced with a proposed major public policy shift, the results suggest readiness for change assessments may assist public agencies with managing major regulatory change.
\end{abstract}

Keywords: aviation safety, organizational change, public policy, readiness for change, safety

\section{Introduction}

The increasing acceleration of technological innovation, changing government regulations, political events, and a dynamic economic environment are major catalysts that require ongoing and often major organizational change (Pfeffer, 1994; Fuioaga, 2012). Cummings and Worley (2014) describe change efforts as moving the organization in a particular direction-- from a current state to a desired state. However, defining what is the "desired state" is often a point of contention among organizational stakeholders, which is often the case with many proposed regulations or policies Cummings et al (2014). Holt, Armenakis, Feild and Harris (2007) describe three stages of successful change implementation: 1) readiness to change, 2) adoption, and 3) institutionalization. Arguably, the first step, readiness to change, may be the most important (Armenakis, Harris, and Mossholder, 1993; Fuioaga, 2012). Understanding an organization's readiness to change can help guide organizational leaders or regulators as they approach change and identify the optimum change strategies (Armenakis, Harris, 2009).

This research discusses a case study from the domestic aviation repair station industry and the industry's readiness for a proposed regulatory change - Safety Management Systems (SMS). Coupled with aviation's increasing technological complexity, growth in general and commercial aviation air traffic, and changes in the composition of the air transport fleet, the FAA's workload focus needs to shift given its limited resources (AIN, 2012; Boeing, 2011; FAA, 2011). Thus, the FAA is shifting away from a traditional enforcement model of safety oversight to a partnership model that promotes safety through self-responsibility at the industry level (AIN, 2012; Gilligan, 2016). SMS is a fundamental component of this regulatory shift (AIN, 2012; Gilligan, 2016; Lercel, 2013). SMS promotes safety through self-responsibility at the industry level and is considered a comprehensive approach to managing risk in aviation and other high-consequence industries (FAA, 2018). The proposed SMS regulation has met stiff resistance from the repair station industry; predominately because many perceive the regulation to be of no benefit 
and overly burdensome (AEA, 2009; AOPA, 2009; FR, 2010; SBA, 2009). The focus of this research is not to support or debate a specific regulatory position but rather gain insight into how readiness for change may affect the proposed or desired altered state. The repair station industry's readiness for change may be low, which may be a significant contributing factor to their negative perception of this proposed policy. Holt, et al. (2007) argue the first step in a successful change initiative is creating a readiness for change; while Pond, Armenakis, and Green, (1984) and Fox, Ellison, and Keith (1988) suggest that assessing an organizations readiness for change may help change agents gauge the state of readiness and better develop effective change strategies.

\section{Theoretical Framework}

The struggle of organizational change may be exemplified by Lewin's (1951) Force-Field Analysis Model (Figure 1), which describes change as a battle between two opposing forces - the forces for change (positive) and the forces against change (negative). The forces for change push the organization towards the desired state, while the forces against change resist any movement and attempt to maintain the status quo. Lewin (1951) describes these forces as not only having direction (positive or negative), but also as having varying levels of magnitude.

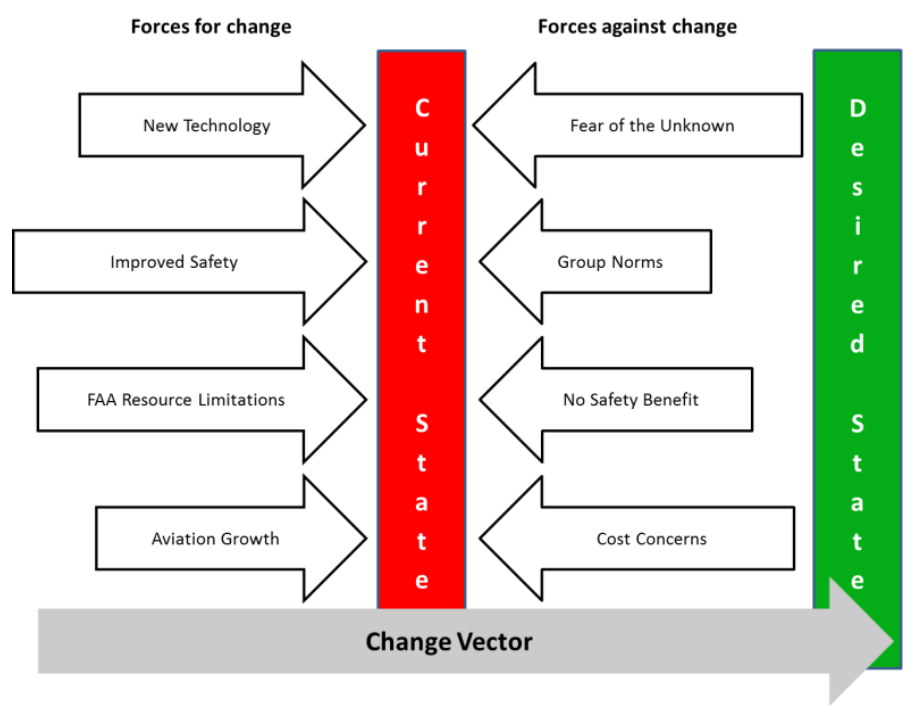

Figure 1. Force-field analysis model, adapted from Cummings and Worley (2014)

Drawing upon the science of physics, a force is defined as a vector quantity, having both magnitude and direction (Lindenfeld, White Brahmia, 2011). Referring to Figure 1, Lewin's (1951) model indicates that for an organization to move from the current state to the desired state, an unbalanced condition must exist where the forces for change are greater than the forces against change. In other words, for change to occur the sum of all forces must be positive, resulting in an overall vector moving the organization towards the desired state. Therefore, Lewin's model suggests that this vector, as illustrated in Figure 2, may be defined as a "change vector."

A common and often powerful negative force working against a change vector is stakeholder resistance (Erwin \& Garman, 2010; Maurer, 1996). Armenakis, Harris, and Mossholder (1993) suggest that by creating a readiness for change, organizations may reduce the stakeholder's resistance and may increase their support for the change; thus, implying that readiness for change may contribute to organizations achieving a change vector. Readiness for change relates to resistance to change, but the two are distinctly different (Armenakis et al., 1993). Readiness for change is the "cognitive precursor to the behaviors of either resistance to, or support for, a change effort" (Armenakis et al., 1993, pp. 681-682). Backer (1995, pp. 22) describes readiness for change as “...people's beliefs, attitudes, and intentions regarding the extent to which changes are needed and their perception of individual and organizational capacity to successfully make those changes." Successful change initiatives are dependent upon an appropriate level of readiness-one of the most important factors in gaining initial support (Armenakis et al., 1993; Armenakis, Harris, \& Feild, 1999).

A review of the literature found little evidence regarding research in the area of public policy initiatives that may affect change across an industry community comprised of thousands of organizations. A literature search using the terms "organizational change", "readiness for change", and "regulation" or "regulatory" resulted in 1,841 peers - reviewed 
journal articles. To keep the review manageable, the search was limited to articles published between June 2005 and June 2018. Articles in non-English or related to biological, political, social, or environmental change were discarded. A review by title of the newest 250 and the oldest 250 articles found 54 article titles that suggested they may relate to readiness for public policy or regulatory change. However, reviewing these articles found none were directly related to assessing an industry's readiness for policy change. These findings are supported by Weiner (2009) and Weiner, Amick, and Lee (2008) who also found a preponderance of the research focused on individuals, targeted small groups, or single organizations, with no mention of organizational change driven by new public policy. Most research regarding organizational change and resistance to change typically focus on characteristics associated with individuals within an organization (Jones, Renae A.; Jimmieson, Nerina L.; Griffiths, Andrew, 2005). Bouckenooghe (2010) found that change readiness theory and measurement overwhelmingly focus on the individual level but researchers often apply these findings incorrectly to an organization's readiness for change. However, from the literature one can infer that readiness for change is as important to a major public policy change as it is to a smaller scale change initiative at the individual or organizational level. Gaining perspective of an industry's readiness for change may provide regulators valuable empirical data that may assist them in deciding whether to move forward with the proposed policy, modify the policy, or develop an alternative strategy to improve the industry's readiness for change - helping to create a change vector.

Neves (2009) presents three dimensions of readiness for change: self-efficacy, change appropriateness, and personal valence; while Cunningham, Woodward, and Shannon (2002) found that employees with higher job-change self-efficacy reported higher readiness for change and contributed more to the change intervention. Determinants of change efficacy include familiarity and organizational support. Efficacy is expected to be high when familiarity with the change is high and they perceive the organization will provide them the resources and support to succeed (Shea, Jacobs, Esserman, Bruce, \& Weiner, 2014). Ironically, the FAA SMS Aviation Rulemaking Committee (ARC) suggested that a low level of familiarity among stakeholders maybe a contributing factor to the industry's resistance to SMS, (FAA 2010) stating:

"...the team recognized that smaller organizations currently have less of an understanding of SMS and their responses may reflect fears of the unknown", and goes on to say, "it appears concerns and issues may be due to a lack of or misunderstanding of SMS. Comments [submitted] generally appear to be looking negatively on SMS without knowing all there is needed to know."

The literature confirmed that many repair station representatives, especially small organizations, were resistant to SMS compliance, with many strongly opposed to any such requirement (Lercel, Patankar, 2011). Many in the repair station industry and the FAA consider SMS a major change or shift in how the industry and FAA will manage safety in the future (Lercel, 2013), which Burke (2004) suggests organizations and individuals are especially resistant to this type of change.

Armenakis et al. (1993) and Neves (2009) suggest that readiness for change is contingent upon organizational stakeholder's level of familiarity with the proposed change, agreement that the change is appropriate, and their level of efficacy and valence. Shea, et al. (2014), Neves (2009), Madsen, Miller, \& Cameron (2005) suggest that familiarity has a significant effect on appropriateness, efficacy, and valence. This suggests that an appropriate level of familiarity with SMS across the repair station industry is a significant factor in achieving policy adoption.

Familiarity with the proposed change is one factor that must be relatively high among members in order to achieve overall support (Cummings, et al., 2014; Armenakis, Harris, 2009). In order for regulators to create a change vector towards policy adoption, a majority of the stakeholders must first have a high level of familiarity with the policy. If familiarity with the proposed policy is low, the literature suggests that the natural tendency will be to resist or disagree (Cummings, et al., 2014). Second, a majority of stakeholders familiar with the policy must also have a high level of agreement that the policy is appropriate and provides positive valence and efficacy (Armenakis, et al, 2009; Neves, 2009). If stakeholders with a high level of familiarity also have a high level of agreement with appropriateness, efficacy, and valence, then regulators are more likely to create a change vector through strategies aimed at ensuring a majority of the population have a high level of familiarity with the policy.

Readiness may be assessed using survey research methodologies, which includes questionnaires, interviews, and observations (Pond, Armenakis, and Green, 1984; Fox, et al., 1988). Although qualitative methods provide a greater depth of information, quantitative methods offer change agents and researchers an efficient means to gather information across a large and dispersed population in a relatively short time (Isabella, 1990). However, the current survey instruments are lengthy and not practical for use in busy organizational or industry settings (Holt, et al., 2007). In addition, Weiner, et al (2008) found ambiguity and disagreement regarding readiness for change concepts; 
furthermore, they found limited evidence of reliability or validity for most measures of change readiness. This research focused on gaining perspective of industry's readiness for policy change along with identifying potential strategies for overcoming the current policy gridlock and not testing a particular hypothesis or determining causation In addition, this research involved surveying a large population of very busy aviation executives; therefore, researchers developed an abbreviated survey instrument based on the research of Armenakis (2011) and Neves (2009) with the hopes of achieving a relatively high response rate.

\section{Methodology}

This study attempted to gain perspective of the repair station industry's readiness for SMS policy adoption by evaluating the organization's designated FAA accountable manager's familiarity with SMS (Familiarity), perceived level of SMS appropriateness (Appropriateness), level of efficacy or adaptability (Efficacy), and the safety benefits of SMS (Valence). The FAA defines accountable manager (FAA, 2017) as, "the person designated by the certificated repair station (CRS) who is responsible for and has the authority over all repair station operations that are conducted under part 145, including ensuring that repair station personnel follow the regulations and serving as the primary contact with the Federal Aviation Administration (FAA)."

This research recruited participants by utilizing publicly available information obtained from the FAA's repair station and air agency database, which provides detailed information regarding all FAA certificated repair stations. This information includes the organization's name, address, number of employees, repair station ratings, and the name and email address of the repair station's accountable manager. The researcher emailed a web-based online survey instrument to the population of $4277(\mathrm{~N}=4277)$ accountable managers using the Qualtrics Online Survey Software.

Table 1. Sample survey questions

\begin{tabular}{|c|c|c|c|}
\hline Area of Measure & Survey Questions & Variable Name & Measure \\
\hline Familiarity & $\begin{array}{l}\text { To what extent are you familiar with Safety Management } \\
\text { Systems? }\end{array}$ & SMS Familiarity & Likert \\
\hline Familiarity & $\begin{array}{l}\text { To what extent are you familiar with the proposed SMS } \\
\text { regulation? }\end{array}$ & $\begin{array}{l}\text { SMS Rule } \\
\text { Familiarity }\end{array}$ & Likert \\
\hline Valence & SMS improves the safety of my organization. & $\begin{array}{l}\text { Safety } \\
\text { Performance }\end{array}$ & Likert \\
\hline Valence & SMS will reduce maintenance errors in my organization & $\begin{array}{ll}\text { SMS } & \text { Reduces } \\
\text { Errors } & \end{array}$ & Likert \\
\hline Appropriateness & $\begin{array}{l}\text { There are legitimate reasons why the repair station } \\
\text { industry needs to implement an SMS. }\end{array}$ & SMS Legitimacy & Likert \\
\hline Appropriateness & Repair stations should have an SMS. & $\begin{array}{l}\text { SMS } \\
\text { Appropriateness }\end{array}$ & Likert \\
\hline Efficacy & $\begin{array}{l}\text { My organization's senior leaders have encouraged all of } \\
\text { us to embrace SMS. }\end{array}$ & $\begin{array}{l}\text { Leadership } \\
\text { Support }\end{array}$ & Likert \\
\hline Efficacy & $\begin{array}{l}\text { I do not anticipate any problems adjusting to the work I } \\
\text { will have if SMS is adopted. }\end{array}$ & $\begin{array}{l}\text { Adjusting } \\
\text { SMS }\end{array}$ & Likert \\
\hline
\end{tabular}

Table 1 provides a list of the survey questions used to assess the participants' readiness for change and measured their attitudes and opinions using a five point Likert - type scale (Table 2). A sample size estimate was based on a confidence level of $95 \%$ and a confidence interval of 5\%. The researcher determined a sample size of approximately 350 cases would be adequate based on calculations and confirmation in the literature (Krejcie, \& Morgan, 1970). Overall, researchers retained $439(\mathrm{n}=439)$ usable cases and the average completion rate of each survey was $98.7 \%$. SPSS software was used to conduct statistical correlation and analysis of variance (ANOVA) tests in order to compare the relationships between variables. 
Table 2. Likert-type scale

\begin{tabular}{lll}
\hline Scale & Level of Agreement & Level of Familiarity \\
\hline $\mathbf{1}$ & Strongly Disagree & Not at all \\
\hline $\mathbf{2}$ & Disagree & To a Little Extent \\
\hline $\mathbf{3}$ & $\begin{array}{l}\text { Neither Agree nor } \\
\text { Disagree }\end{array}$ & To Some Extent \\
& Agree & To a Moderate Extent \\
\hline $\mathbf{4}$ & Strongly Agree & To a Large Extent \\
\hline $\mathbf{5}$ &
\end{tabular}

\section{Results}

All respondents either were owners of, or employed by, a part 145 repair station with the following job position breakdown: $32 \%$ manager, $18 \%$ vice president or general manager, $16 \%$ director, $14 \%$ owner, $9 \%$ chief executive officer or president, and $11 \%$ other.

Table 3. Respondent's organizational size vs. domestic repair station population

\begin{tabular}{lllll}
\hline $\begin{array}{l}\text { Organizational } \\
\text { Size }\end{array}$ & $\begin{array}{l}\text { Number of Employees } \\
\text { in the Organization }\end{array}$ & $\begin{array}{l}\text { Number of Respondents } \\
\mathbf{n = 4 3 9}\end{array}$ & $\begin{array}{l}\text { Sample } \\
\text { Percentage }\end{array}$ & $\begin{array}{l}\text { Population } \\
\text { Percentage }\end{array}$ \\
\hline Very Small & $1-10$ & 136 & $31 \%$ & $47 \%$ \\
\hline Small & $11-25$ & 80 & $18 \%$ & $18 \%$ \\
\hline Medium & $26-50$ & 58 & $13 \%$ & $12 \%$ \\
\hline Large & $51-100$ & 55 & $13 \%$ & $8 \%$ \\
\hline Very Large & greater than 100 & 110 & $25 \%$ & $15 \%$ \\
\hline
\end{tabular}

Table 3 provides a breakdown of respondents by organizational size, illustrating the largest number of respondents (31\%) were from organizations categorized as Very Small (1-10 employees). The sample distribution across the five categories of Organizational Size was not representative of the population distribution; however, the sample size for each category was sufficient to allow for correlation tests and mean comparisons.

Table 4. Correlation table

\begin{tabular}{|c|c|c|c|c|c|c|c|c|c|c|}
\hline Variable & $\mathbf{M}$ & SD & 1 & 2 & 3 & 4 & 5 & 6 & 7 & 8 \\
\hline Organizational Size & ---- & ---- & ---- & & & & & & & \\
\hline SMS Familiarity & 3.28 & 1.23 & $.420^{* *}$ & & & & & & & \\
\hline $\begin{array}{l}\text { 3. SMS } \\
\text { Familiarity }\end{array}$ & 2.86 & 1.22 & $.382^{* *}$ & $.763^{* *}$ & & & & & & \\
\hline 4. Safety Performance & 3.29 & 1.24 & $.358^{* *}$ & $.502^{* *}$ & $.366^{* *}$ & & & & & \\
\hline $\begin{array}{l}\text { 5. SMS } \\
\text { Errors }\end{array}$ & 3.22 & 1.23 & $.370^{* *}$ & $.458^{* *}$ & $.353^{* *}$ & $.843^{* *}$ & & & & \\
\hline 6. SMS Legitimacy & 3.21 & 1.18 & $.351^{* * *}$ & $.452^{* *}$ & $.350^{* *}$ & $.789^{* *}$ & $.792^{* *}$ & & & \\
\hline $\begin{array}{l}\text { 7. SMS } \\
\text { Appropriateness }\end{array}$ & 3.30 & 1.25 & $.357^{* *}$ & $.485^{* *}$ & $.373^{* *}$ & $.859^{* *}$ & $.911^{* *}$ & $.811^{* *}$ & & \\
\hline 8. Leadership Support & 2.95 & 1.19 & $.371^{* *}$ & $.537^{* *}$ & $.425^{* *}$ & $.704^{* *}$ & $.695^{* *}$ & $.636^{* *}$ & $.686^{* *}$ & . \\
\hline Adjusting to SMS & 2.90 & 1.25 & $.312^{* *}$ & $.452^{* *}$ & $.352^{* *}$ & $.727^{* *}$ & $.729^{* *}$ & $.722^{* *}$ & $.716^{* *}$ & $.687^{* *}$ \\
\hline
\end{tabular}

**Correlation is significant at the 0.01 level (2-tailed). 
Spearman Rho correlations were performed comparing the variables and resulted in all correlations being significant (Table 4). ANOVA tests compared group differences across the areas of familiarity, appropriateness, efficacy, and valence. This discussion will focus on the more significant correlations. It should be noted that high correlations suggest an association, but do not represent causality.

\subsection{SMS Familiarity}

Overall, the industry's level of familiarity with SMS was low, with only $30.5 \%$ of organizations having had some type of SMS training. Only $12.5 \%$ of repair stations have an operational SMS, and 51.5\% have not started any SMS development or implementation activities. The mean score of the industry's level of SMS Familiarity is 3.28 ( $\mathrm{M}=$ $3.28, \mathrm{SD}=1.23$ ), which equates closely to a response of "to some extent", while SMS Rule Familiarity is lower with a mean score of $2.86(\mathrm{M}=2.86, \mathrm{SD}=1.22)$. Correlation results indicate that larger organizations tend to be more familiar with SMS.

\subsection{SMS Appropriateness}

When participants were asked if they believe there are legitimate reasons why the repair station industry needs to implement SMS (SMS Legitimacy) the responses resulted in an overall mean score of 3.21 ( $\mathrm{M}=3.21, \mathrm{SD}=1.18)$, which closely equates to a response of "neither agree nor disagree." Overall, $45.9 \%$ of respondents either agreed or strongly agreed, $25.5 \%$ either disagreed or strongly disagreed, and $28.6 \%$ neither agreed nor disagreed. When asked if repair stations should have an SMS (SMS Appropriateness), $46.8 \%$ of respondents either agreed or strongly agreed, $31.9 \%$ either disagreed or strongly disagreed, and $21.3 \%$ neither agreed nor disagreed.

There was a significant correlation between Organizational Size and the response to the questions of SMS Legitimacy and SMS Appropriateness (Table 4), indicating that as Organizational Size increased the level of agreement with SMS Legitimacy and SMS Appropriateness increased significantly (Figure 3). In addition, there was a significant correlation between SMS Legitimacy and SMS Appropriateness.

\subsection{Efficacy}

Participants were asked if they anticipate any problems adjusting to the work they will have if SMS is adopted (Adjusting to SMS), which resulted in a mean score of 2.90 or "neither agree nor disagree" $(\mathrm{M}=2.90, \mathrm{SD}=1.25)$. Overall $37.6 \%$ of participants either disagreed or strongly disagreed, while $38.2 \%$ either agreed or strongly agreed, $24.2 \%$ neither agreed nor disagreed. Regarding Leadership Support, the mean score was 2.95 ( $\mathrm{M}=2.95, \mathrm{SD}=1.19)$; $31.9 \%$ either agreed or strongly agreed, 36.3\% neither agreed nor disagreed, and 31.8\% disagreed or strongly disagreed with their organization's level of SMS support.

There was a significant correlation between Adjusting to SMS and Organizational Size $(r=.312, p<.01)$, which indicates that as Organizational Size increases then participants are in greater agreement that they can adapt to SMS. There was a significant correlation between Organizational Size and Leadership Support $(r=.371, p<.01)$, which indicates that as Organizational Size increases the level of Leadership Support increases.

\subsection{Valence}

Overall survey results found that participants neither agreed nor disagreed that SMS improves the safety of their organization (Safety Performance; $\mathrm{M}=3.29, \mathrm{SD}=1.24$ ); $48.5 \%$ either agreed or strongly agreed, $23.2 \%$ either disagreed or strongly disagreed, and $28.3 \%$ neither agreed nor disagreed. When asked if SMS helps repair stations reduce maintenance errors (SMS Reduces Errors; $\mathrm{M}=3.22, \mathrm{SD}=1.23$ ) $46.3 \%$ either agreed or strongly agreed, $25.4 \%$ either disagreed or strongly disagreed, and $28.3 \%$ neither agreed nor disagreed.

There were significant correlations between Organizational Size and Safety Performance $(r=.358, p<.01)$ and SMS Reduces Errors $(r=.370, p<.01)$, which indicates that as organizational size increases so does the level of agreement that SMS improves safety performance and reduces maintenance errors.

\subsection{Correlating SMS Familiarity With SMS Appropriateness, Efficacy, and Valence}

\subsubsection{SMS Familiarity: SMS Appropriateness}

Two-way independent ANOVA tests of the main effect of SMS Familiarity on SMS Legitimacy were significant, $\mathrm{F}(4,405)=12.066, \mathrm{p}<.01, \eta^{2}=.106$, indicating that as SMS Familiarity increased then the opinion that there are legitimate reasons for SMS increased. Post hoc tests found respondents familiar with SMS to a "large extent" (M = $4.06, \mathrm{SD}=.92)$, to a "moderate extent" $(\mathrm{M}=3.46, \mathrm{SD}=1.07)$, to "some extent" $(\mathrm{M}=2.96, \mathrm{SD}=1.10)$ agree significantly $(\mathrm{p}<.01)$ more than respondents "not at all" familiar $(\mathrm{M}=2.43, \mathrm{SD}=1.09)$ that there are legitimate reasons for repair stations to implement SMS. The main effect of Organizational Size on SMS Legitimacy was also 
significant, $\mathrm{F}(4,405)=4.663, \mathrm{p}<.01, \eta^{2}=.044$. However, the interaction between SMS Familiarity and Organizational Size was not significant $(\mathrm{p}=.559)$, indicating that the effect of SMS Familiarity on SMS Legitimacy was not dependent on Organizational Size.

Two-way independent ANOVA tests of the main effect of SMS Familiarity on SMS Appropriateness were significant, $\mathrm{F}(4,409)=15.976, \mathrm{p}<.01, \eta^{2}=.135$, indicating that as SMS Familiarity increased then the level of agreement with SMS Appropriateness increased. Tukey post hoc tests found respondents familiar with SMS to a "large extent" $(\mathrm{M}=4.24, \mathrm{SD}=.98)$, to a "moderate extent" $(\mathrm{M}=3.63, \mathrm{SD}=1.02)$, and to "some extent" $(\mathrm{M}=3.01$, $\mathrm{SD}=1.14)$ agree significantly $(\mathrm{p}<.01)$ more than respondents "not at all" familiar $(\mathrm{M}=2.44, \mathrm{SD}=1.02)$ that $\mathrm{SMS}$ is appropriate for repair stations. Those familiar with SMS to a "large extent" and to a "moderate extent" also agree significantly $(\mathrm{p}<.01)$ more than those familiar to "some extent" and a "little extent" $(\mathrm{M}=2.89, \mathrm{SD}=1.21)$ that SMS is appropriate, while to a "large extent" also agrees significantly $(\mathrm{p}<.01)$ more than "moderate extent."

The main effect of Organizational Size on SMS Appropriateness was also significant, $F(4,409)=5.815, p<.01, \eta 2$ $=.054$. However, the interaction between SMS Familiarity and Organizational Size was not significant $(\mathrm{p}=.432)$, indicating that the effect of SMS Familiarity on SMS Appropriateness was not dependent on Organizational Size.

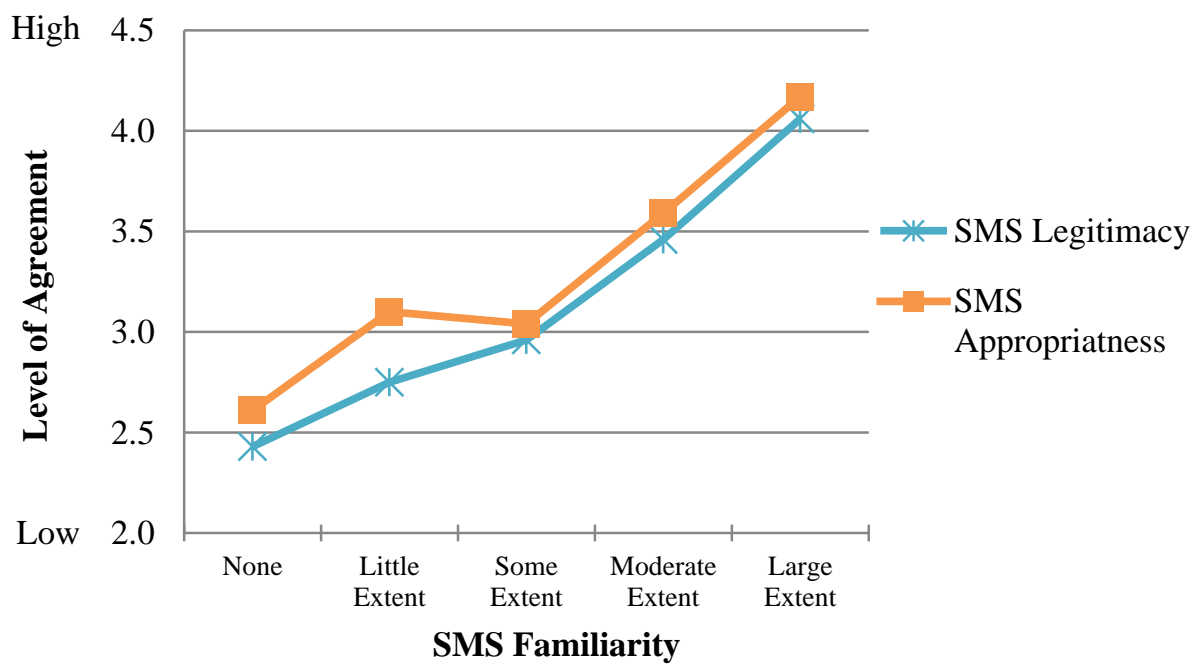

Figure 2. Comparison of level agreement with SMS legitimacy/appropriateness by organizational size

Figure 2 illustrates that as SMS Familiarity increased, the level of agreement with SMS Legitimacy and SMS Appropriateness increased across all categories of Organizational Size, with the overall mean scores illustrating an almost linear relationship.

\subsubsection{SMS Familiarity: SMS Efficacy}

A two-way independent ANOVA found that SMS Familiarity, $\mathrm{F}(4,405)=17.425, \mathrm{p}<.01, \eta^{2}=.147$, and Organizational Size, $F(4,405)=2.791, p<.05, \eta^{2}=.027$, both had a significant main effect on Adjusting to SMS. Again, there was no significant $(\mathrm{p}=.493)$ interaction between SMS Familiarity and Organizational Size, which indicates that the effect of SMS Familiarity on Adjusting to SMS was not dependent on Organizational Size.

Similarly, ANOVA results found significant main effects of SMS Familiarity, $F(4,405)=24.880, p<.01, \eta^{2}=.197$, and Organizational Size, $F(4,405)=3.367, \mathrm{p}<.05, \eta^{2}=.032$, on Leadership Support. Also, there was no significant $(\mathrm{p}=.556)$ interaction between SMS Familiarity and Organizational Size, which again indicates that the effect of SMS Familiarity on Leadership support was not dependent on Organizational Size. Figure 3 illustrates an almost linear relationship between Adjusting to SMS, Leadership Support, and SMS Familiarity; as the respondent's familiarity with SMS increases then so does their level of efficacy. 


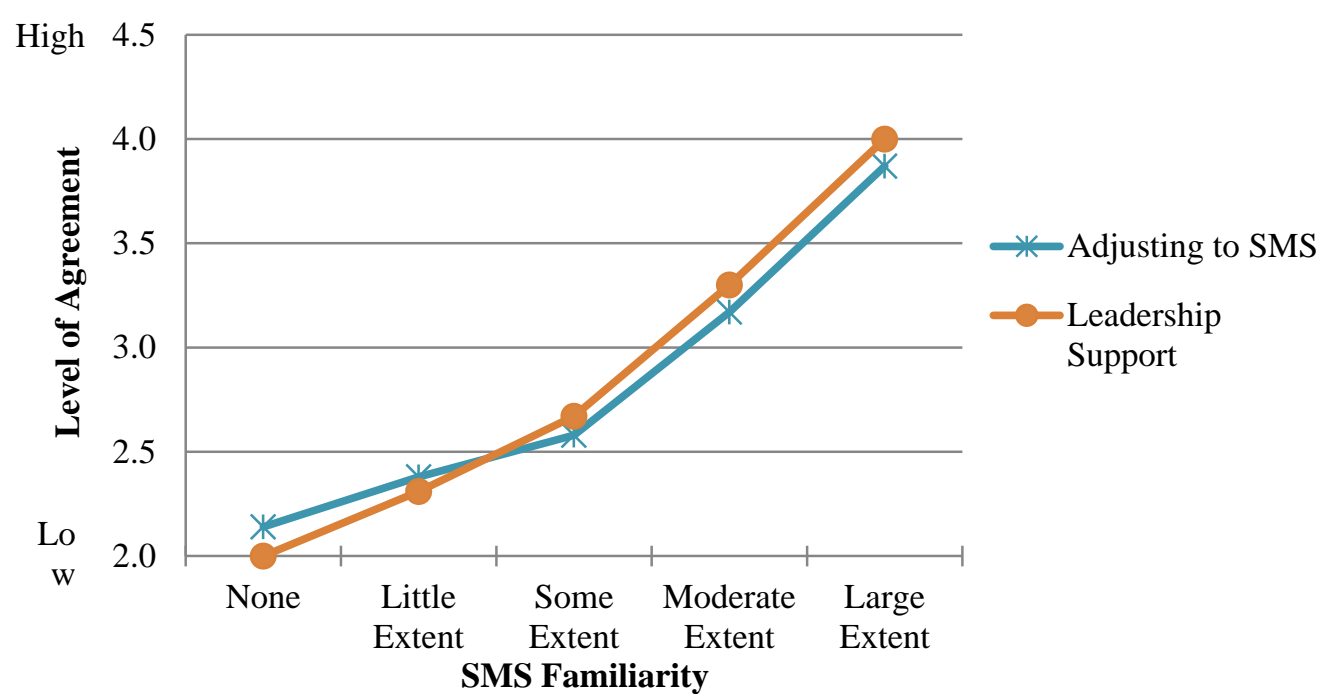

Figure 3. Effect of SMS familiarity on adjusting to SMS and leadership support

\subsubsection{SMS Familiarity: Valence}

A two-way independent ANOVA found that SMS Familiarity, $\mathrm{F}(4,409)=16.996, \mathrm{p}<.01, \eta^{2}=.143$, and Organizational Size, $\mathrm{F}(4,409)=5.623, \mathrm{p}<.01, \eta^{2}=.052$, both had a significant main effect on Safety Performance. However, there was no significant $(\mathrm{p}=.446)$ interaction between SMS Familiarity and Organizational Size, which indicates that the effect of SMS Familiarity on Safety Performance was not dependent on Organizational Size.

ANOVA results found significant main effects of SMS Familiarity, $F(4,409)=15.980, p<.01, \eta^{2}=.118$, and Organizational Size, $F(4,409)=5.937, p<.01, \eta^{2}=.055$, on SMS Reduces Errors. Again, there was no significant $(\mathrm{p}=.637)$ interaction between SMS Familiarity and Organizational Size, which indicates that the effect of SMS Familiarity on SMS Reduces Errors was not dependent on Organizational Size. Figure 4 illustrates an almost linear relationship between Adjusting to SMS, Leadership Support, and SMS Familiarity; as the respondent's familiarity with SMS increases so does their level of valence.

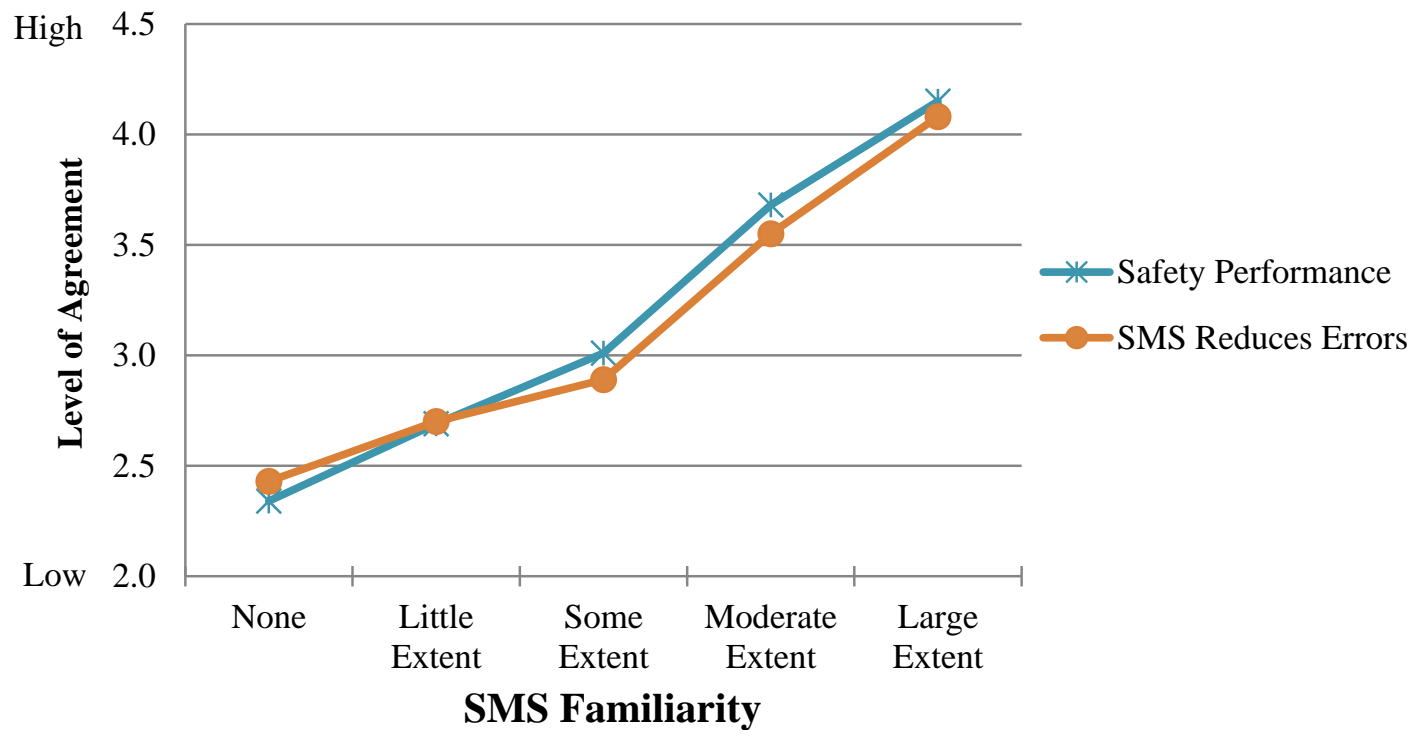

Figure 4. Effect of SMS familiarity on safety performance and SMS reduces errors 


\section{Discussion}

The findings from this research support the past literature; suggesting that familiarity with a proposed change may significantly influence the stakeholder's opinion of appropriateness, efficacy, and valence (Shea, et al., 2014; Neves, 2009; Madsen, et al., 2005). Furthermore, this study indicates that the use of change readiness assessments in regulatory policy initiatives may help regulators to gain perspective on an industry's readiness for regulatory change and identify potential strategies for improving the level of readiness across a large industry group and creating an unbalanced sum of forces moving towards a change vector.

The research results suggest the repair station industry's overall level of SMS Familiarity and SMS Rule Familiarity is low, especially with the Very Small and Small organizations. Less than a third of all respondents indicated that their organization has had some type of SMS training and only $12.5 \%$ indicated that their organization has an operational SMS. In addition, the respondents' overall level of agreement with SMS Appropriateness, Valence, and Efficacy was low, with less than 50\% indicating agreement.

However, as the respondents' level of Familiarity increased their level of agreement with Appropriateness, Efficacy, and Valence increased significantly; the effect of Familiarity was similar across all five categories of Organizational Size. Appropriateness, Efficacy, and Valence increased dramatically when the respondents' level of Familiarity rose above "some extent"; Figures 2-4 depict a point of inflection at the "some extent" level of Familiarity. Ultimately, respondents familiar with SMS to a "large extent" had Appropriateness, Efficacy, and Valence scores near or above "agree." These findings suggest that efforts aimed at increasing the industry's level of familiarity may assist regulators with improving the state of change readiness.

Approximately 70\% of the repair station population is comprised of Very Small or Small organizations (Table 3); thus, significant support from these smaller organizations is required for SMS policy adoption. However, only $21.3 \%$ of the respondents from Very Small organizations and 38.8\% of the respondents from Small organizations are at a Familiarity level above "some extent". In addition, only $13.3 \%$ of the respondents from Very Small organizations and $23.8 \%$ of the respondents from Small organizations are familiar with the proposed SMS rule above a level of "some extent." Thus, regulators may consider developing strategies focused on raising the level of Familiarity across these two groups.

\section{Limitations and Future Research}

This research found that the use of change readiness assessments may provide rich information that contributes to a body of discourse that may help address policy gridlock. However, change readiness studies in the area of regulatory change that may affect a large industry group are rare. In addition, there are few mature readiness assessment instruments. Compared to previous survey instruments, this research utilized a very brief instrument aimed at obtaining a high response rate across a population of busy business executives. Although this research was successful in achieving a high response rate, future research is required to develop a concise, reliable and valid survey instrument. One area that requires further investigation is the relational direction between the variables; for example, knowledge increases readiness requires further research to confirm and support the current research. Several unexplored factors require further exploration and were not accounted for in this research study but may have influenced the research participants' responses and contribute to the industry's policy resistance, such as media reports, opinions of industry leaders, perceived costs of compliance and need for regulation, apprehensive view of the FAA, or a general fear of the unknown.

Research limitations exist concerning possible differences across organizations and how they approach, communicate, and execute change. These differences can significantly affect the levels of familiarity, appropriateness, efficacy, and valence. This study could not control these differences. In addition, this survey asked individuals to measure their own levels of familiarity but did not test for a level of familiarity. This provided a somewhat subjective measurement of familiarity.

In addition, this study focused on readiness from an industry perspective and did not involve the FAA. FAA personnel would be the frontline regulators regarding SMS compliance, therefore, their opinions regarding this proposed SMS compliance solution are extremely valuable. In addition, by investigating the attitudes and opinions of the FAA inspectors regarding SMS, change agents can understand these forces and better develop effective SMS development and implementation strategies. Conducting research on FAA personnel is an important next step in advancing SMS adoption. 


\section{Conclusion}

The literature prominently illustrates the importance of creating a state of readiness by building awareness of the proposed change and educating and training stakeholders; thereby, overcoming the natural resistance to change (Rowden, 2001; Armenakis, et al., 1993). Although this research was limited in scope and intended as an initial exploration of change readiness concepts across a large industry faced with a proposed major public policy shift, the results suggest readiness for change assessments may assist public agencies with managing major regulatory change. These assessments may provide both regulatory agencies and change agents valuable insight into the basis of stakeholder resistance. Furthermore, by gaining perspective on the affect change readiness may have on stakeholder resistance, regulators may better focus change efforts and improve the efficiency of the change process. While this study found the repair station's readiness for change was relatively low, the data suggest that efforts aimed at improving the stakeholder's knowledge of SMS may improve their overall level of readiness - contributing to the forces for change needed to create a change vector.

\section{References}

Aircraft Electronics Association (AEA). (2009). Avionics News "AEA challenges FAA on its broad-based proposal for SMS". Retrieved November 8, 2010, from http://www.aea.net/governmentaffairs/regulatoryupdates_item.asp?ID=28

Aircraft Owners and Pilots Association (AOPA). (2009). Proposed safety management systems sparks questions. Retrieved December 19, 2011, from http://www.aopa.org/advocacy/articles/2009/091028faa.html

Armenakis, A., Brown, S., \& Mehta, A. (2011). Organizational Culture: Assessment and Transformation. Journal of Change Management, 11(3), 305-328. https://doi.org/10.1080/14697017.2011.568949

Armenakis, A. A., \& Harris, S. G. (2009). Reflections: our Journey in Organizational Change Research and Practice. Journal of Change Management, 9(2), 127-142. https://doi.org/10.1080/14697010902879079

Armenakis, A. A., Harris, S. G., \& Feild, H. S. (1999). Making change permanent: a model for institutionalizing change. In W. Pasmore and R. Woodman (Eds), Research in Organization Change and Development (vol. XII, pp. 97-128). Greenwich, CT: JAI Press, Inc. https://doi.org/10.1016/S0897-3016(99)12005-6

Armenakis, A. A., Harris, S. G., \& Mossholder, K. W. (1993). Creating readiness for organizational change. Human Relations, 46(6), 681-703. https://doi.org/10.1177/001872679304600601

Aviation International News (AIN). (2012). Air Charter Safety Foundation Safety Symposium Focuses on SMS, FAA Enforcement Actions. Retrieved May 12, 2011, from http://www.ainonline.com/aviation-news/2012-05-09/acsf-safety-symposium-focuses-sms-faa-enforcement-acti ons

Backer, T. E. (1995). Assessing and enhancing readiness for change: implications for technology transfer. NIDA Res Monogr, 155, 21-41.

Boeing Commercial Airplanes. (2011). Current Market Outlook, 2011-2030.

Bouckenooghe, D. (2010). Positioning change recipients' attitudes toward change in the organizational change literature. Journal of Applied Behavioral Science, 46, 500-531. https://doi.org/10.1177/0021886310367944

Burke, W. (2004). Organization Development: What We Know and What We Need to Know Going Forward. Retrieved December 28, 2012, from http://www.g-rap.org/docs/icb/warner_burke_2004-organisation_development.pdf

Cummings, T., \& Worley, C. (2014). Organization Development and Change (10th ed.). Stamford, CT. Cengage Learning.

Cunningham, C. E., Woodward, C. A., Shannon, H. S., MacIntosh, J., Lendrum, B., Rosenbloom, D., \& Brown, J. (2002). Readiness for Organizational Change: A longitudinal study of workplace, psychological and behavioral correlates. Journal of Occupational and Organizational Psychology, 75, 377-392. https://doi.org/10.1348/096317902321119637

Erwin, D. G., \& Garman, A. N. (2010). Resistance to organizational change: linking research and practice. Leadership and Organizational Development Journal, 31(1), 39-56. https://doi.org/10.1108/01437731011010371 
Federal Aviation Administration (FAA). (2010). Recommendations of the aviation safety management system aviation rulemaking committee. Retrieved March 13, 2019, from http://www.regulations.gov/\#!documentDetail;D=FAA-2009-0671-0094

Federal Aviation Administration (FAA). (2011). Repair station database. Retrieved March 13, 2019, from http://av-info.faa.gov/repairstation.asp

Federal Aviation Administration (FAA). (2017, October 6). Guide for Developing and Evaluating Repair Station and Quality Control Manuals. Advisory Circular 145-9A.

Federal Aviation Administration (FAA). (2018). SMS Explained. Retrieved October 3, 2018, from https://www.faa.gov/about/initiatives/sms/explained/

Federal Register (FR). (2010). Safety management systems for Part 121 certificate holders: A proposed rule by the Federal Aviation Administration, Notice of Proposed Rulemaking. Retrieved March 13, 2019, from http://www.federalregister.gov/articles/2010/11/05/2010-28050/safety-management-systems-for-part-121-certifi cate-holders

Fox, D. G., Ellison, R. L., \& Keith, K. L. (1988). Human Resource Management, an Index and its Relationship to Readiness for Change. Public Personnel Management, 17(3), 297-302.

Fuioaga (Basu), P. (2012). Readiness for Change as a Key Factor in Implementing Organizational Changes. Calitatea, 13(5), 151-154. Retrieved from https://search.proquest.com/docview/1261380673?accountid=13360

Gilligan, P. (2016, June 14). Strong Partnerships are the Key to Safety. 2016 FAA-EASA Aviation Safety Conference. Washington, DC.

Holt, D. T., Armenakis, A. A., Feild, H. S., \& Harris, S. G. (2007a). 'Readiness for organizational change: the systematic development of a scale. Journal of Applied Behavioral Science, 43(2), 232-55. https://doi.org/10.1177/0021886306295295

Isabella, L. A. (1990). Evolving interpretations as a change unfolds: How managers construe key organizational events. Academy of Management Journal, 33, 7-41.

Jones, R. A., Jimmieson, N. L., \& Griffiths, A. (2005, March). The Impact of Organizational Culture and Reshaping Capabilities on Change Implementation Success: The Mediating Role of Readiness for Change. Journal of Management Studies, 42(2), 361-386. https://doi.org/10.1111/j.1467-6486.2005.00500.x

Krejcie, R. V., \& Morgan, D. W. (1970). Determining sample size for research activities. Educational \& Psychological Measurement, 30, Autumn, 607-610. https://doi.org/10.1177/001316447003000308

Lercel, D. (2013, July). Safety Management Systems In FAA Part 145 Repair Stations: Barriers And Opportunities. St. Louis, MO: Center for Aviation Safety Research.

Lercel, D., \& Patankar, M. (2011, February). Applicability-based Model for SMS Compliance by Part 145 Repair Stations. St. Louis, MO: Center for Aviation Safety Research.

Lewin, K. (1951). Field Theory in Social Science. Harper and Row, New York, NY.

Lindenfeld, P., \& White Brahmia, S. (2011). Physics: The First Science. New Brunswick, NJ: Rutgers University Press.

Madsen, S., Miller, D., \& Cameron, J. R. (2005). Readiness for Organizational Change: Do Organizational Commitment and Social Relationships in the Workplace Make a Difference?. Human Resources Development Quarterly, 16(2), Summer. https://doi.org/10.1002/hrdq.1134

Marshak, R. J., \& Grant, D. (2011). Creating Change by Changing the Conversation. O.D. Practitioner, 43(3).

Maurer, R. (1996). Using Resistance to Build Support for Change. Journal for Quality Participation, 19(3), 56-64.

McClellan, J. G. (2011, December). Reconsidering Communication and the Discursive Politics of Organizational Change. Journal of Change Management, 11(4), 465-480. https://doi.org/10.1080/14697017.2011.630508

Neves, P. (2009). Readiness for Change: Contributions for Employee's Level of Individual Change and Turnover Intentions. Journal of Change Management, 9(2), 215-231.

Pfeffer, J. (1994). Competitive Advantage through People - Unleashing the Power of the Workforce. Harvard Business School Press, Boston, MA. 
Pond, S., Armenakis, A., \& Green, S. (1984). The importance of employee expectations in organizational diagnosis. Journal of Applied Behavioral Science, 20, 167-180. https://doi.org/10.1177/002188638402000207

Rowden, R. W. (2001). The Learning Organization and Strategic Change. SAM Advanced Management Journal, 66(3), Summer, 11.

Shea, C., Jacobs, S., Esserman, D., Bruce, K., \& Weiner, B. (2014). Organizational readiness for implementing change: a psychometric assessment of a new measure. Implementation Science, 9(7). https://doi.org/10.1186/1748-5908-9-7

Small Business Administration, Office of Advocacy (SBA). (2009). Comments on FAA's ANPRM on safety management system. Retrieved March 13, 2019, from http://archive.sba.gov/advo/laws/comments/faa09_1021.html

Weiner, B. J., Amick, H., \& Lee, S.-Y. D. (2008). Conceptualization and Measurement of Organizational Readiness for Change: A Review of the Literature in Health Services Research and Other Fields. Medical Care Research and Review, 65(4), August, 379-436. https://doi.org/10.1177/1077558708317802

Weiner, B. J. (2009). A theory of organizational readiness for change. Implementation Science - Biomed Central, 4(67). https://doi.org/10.1186/1748-5908-4-67 